PANDEMIA, SALUD MENTAL COMUNITARIA Y RESPUESTA PÚBLICA.

ENTREVISTA A EMILIANO GALENDE

Svenska Arensburg Castelli 
SVENSKA ARENSBURG CASTELLI

Directora de Extensión de la Universidad de Chile. Psicóloga de la Universidad Diego Portales, Magíster en Psicología Social y Doctora Cum Laude en Psicología Social de la Universidad Autónoma de Barcelona.

Desde el año 2006 se desempeña como académica del Departamento de Psicología de la Facultad de Ciencias Sociales de la Universidad de Chile. En el ámbito profesional, se ha desempeñado en el área de investigación de políticas públicas y en la gestión y planificación de programas relacionados con políticas de género, derechos humanos y atención a víctimas de delito.

Como especialista en psicología jurídica, ha participado de diversas investigaciones, ha presentado en congresos y ha publicado artículos, principalmente sobre victimología y sistema penitenciario. 


\section{PANDEMIA, SALUD MENTAL COMUNITARIA Y RESPUESTA PÚBLICA ENTREVISTA A EMILIANO GALENDE}

Vivimos momentos inéditos y tristes, expuestos a la contingencia de un tiempo pandémico, un tiempo en suspenso, al decir de Pablo Oyarzún, removid@s por vivencias de pérdida que nos inundan de impotencia y temor.

En la prensa, foros remotos y redes sociales se plantea la salud mental como territorio de comprensión del sufrimiento. $\mathrm{Y}$ no es casual: el mundo en el que vivíamos se ha trastocado irremediablemente y eso nos desarma como comunidades y subjetividades, desnuda las precariedades estructurales, territoriales y personales que ya existían previamente. La pandemia ha removido los cimientos de nuestra arquitectura social, las dinámicas cotidianas de interacción cara a cara están congeladas, el distanciamiento físico nos ha llevado a una experiencia de letargo colectivo. En este escenario nos extrañamos de nosotros y de cómo imaginamos el futuro, se despiertan fantasmas, se agudizan prejuicios y desconfianzas que agravan el malestar frente al acontecer.

La Comisión Económica para América Latina y el Caribe (Cepal) emitió un informe en el mes de abril donde proyectaba 30 millones más de personas pobres en América Latina para el final de este año. Lo expuesto en la estrategia de salud mental presentada por la Universidad de Chile para la Mesa Covid-19 apunta a la desigualdad social, la desconfianza en las instituciones y el malestar subjetivo como el germen desde donde se asientan y agudizan las demandas de salud mental en nuestro país. La crisis sanitaria sin precedentes que estamos experimentando desnuda otra crisis que ya estaba siendo denunciada y que se evidencia desde el 18 de octubre de 2019.

La precarización de la vida no es un problema de salud mental, tal como recupera Margot Pujal (2018), para quien es urgente exponer que algunas experiencias de sufrimiento se etiquetan como demandas de salud mental, pero que su contexto desencadenante son cuestiones sociales y políticas, aunque "acaben impactando y expresándose en términos de bienestar/malestar corporal, psíquico o relacional” (Agüero, 2017), pero justamente por ello, su resolución excede al mundo sanitario, porque se trata de condiciones sociales, culturales y de poder adversas a la vida (Pujal, 2018, p. 173). Esta precarización globalizada y masiva que comienza a manifestarse desnuda lo que Rossana Reguillo (2017) explora como reparto inequitativo del riesgo. Es decir, si bien podríamos estar igualmente disponibles para enfermarnos 
por Covid-19, son las personas que viven en situaciones de mayor precariedad quienes se llevan la peor parte.

Pensando en esta relación entre pandemia, salud mental y precariedad colectiva, en el mes de mayo invitamos a conversar a Emiliano Galende, médico, psicoanalista, Profesor Consulto de la Universidad Nacional de Lanús y director de la Revista Salud Mental y Comunidad. Es también ex director y actual integrante del Doctorado en Salud Mental de la Universidad de Lanús, profesor de la Universidad de Granada (España), Universidad de la República (Uruguay) y Universidad de Concepción (Chile). Galende es autor de varios libros y diversos artículos en revistas especializadas sobre salud mental y comunidad.

El año 2018, en una entrevista con Adriana Versi, Emiliano Galende señalaba "tres actores que actúan en salud mental (las instituciones del Estado, los profesionales con incumbencia y los usuarios de la sociedad civil); el Estado es el más importante. No solo por la estructura de los servicios y la cobertura que brinda, sino porque legisla el ordenamiento jurídico que regula la relación del Estado con las personas con sufrimiento mental".

\section{-Usted es un referente en el campo de la salud mental que se enfoca en lo comunitario desde el psicoanálisis. ¿Cómo está pensando el escenario que nos toca vivir en pandemia?}

Bueno, yo trabajo hace muchos años en la universidad, en la organización de los postgrados en salud mental, una salud mental comunitaria que está en desarrollo, con el equipo nuestro de la Universidad Nacional Belgrano. Tuvimos una maestría y hace ya 20 años conseguimos un doctorado con mucho apoyo internacional, un doctorado gestionado a través de los programas de ayuda de la Unión Europea (UE). Yo construí el doctorado, fui director, sigo siendo consultor, y ahí, por supuesto, tenemos relación con el área pública. El programa de doctorado en este momento lleva once ciclos. Los doctorantes provienen de distintos países de Latinoamérica, tenemos un grupo de ex alumnos, hay 32 doctorados dentro del programa, con lo cual se ha formado un colectivo amplio con incidencia en distintos países, especialmente en Colombia, Uruguay, Brasil y Chile.

Actualmente, en Argentina estamos preocupados y atentos, hay un equipo diría yo- intelectual de primer nivel de la salud y también del lado de la gente que venimos de salud mental. Estamos muy ligados, porque en la universidad tenemos un Departamento de Salud Comunitaria que abarca ambas perspectivas: salud colectiva y salud mental comunitaria. Desde allí estamos tratando de generar un enfoque más racional con lo que está pasando con la epidemia, porque las informaciones que 
circulan por televisión o por las redes sociales hacen grandes distorsiones, buscan más sensacionalismo y apuntan más a generar alarma y alerta que a dar información, y como pertenecemos a esta área de salud mental y psicoanálisis, nosotros aportamos mucho en plantear que la fortaleza mayor se da por el entendimiento; mientras más personas tengan una versión más amplia de la situación que está pasando, puede ayudar mucho a que las personas logren calma, tranquilidad y que puedan soportar la incertidumbre. Desde la mirada de salud mental y salud colectiva hay que tener una contextualización más amplia del problema, porque circulan informaciones muy parciales y la gente no lo logra articular.

\section{-Desde el punto de vista de la salud, ¿se han construido una opinión de cómo se ha gestionado esta pandemia?}

Con OPS (Organización Panamericana de la Salud) tenemos un contacto muy fluido porque hemos trabajado más de 20 años, con ellos vamos mirando a nivel internacional, pero por supuesto nos enfocamos en la situación argentina, que es lo que nos convoca a tener respuestas. La epidemia tiene dos aspectos, uno biológico, que es básicamente la infección en el cuerpo y los procesos de enfermedad que desencadena, y lo otro es la respuesta de las personas, las respuestas que cada persona, individualmente, tiene frente a la alteración, incertidumbre y lo que eso está trayendo a su vida. Esto también implica la interrupción de los hábitos de la vida cotidiana y las amenazas que aparecen a futuro.

Cuando hablamos desde la perspectiva de salud, sabemos que la consecuencia de la epidemia es una relación entre la peligrosidad del virus y el sistema inmunológico que tienen los cuerpos. El virus se vio como peligroso porque es un virus nuevo, no conocido y que no tiene inmunidad previa, o sea, se encuentra con cuerpos humanos que no tienen inmunidad para la defensa frente a este virus. Eso hace que siempre la gravedad de la enfermedad esté en relación al grado de inmunidad que puede despertar el organismo frente a la agresión del virus, el contagio. Por eso nos encontramos con aquellas/os que tienen más debilitado el sistema inmunológico por enfermedades previas o por el envejecimiento, que tienen siempre más riesgo de agravamiento de la enfermedad.

Pero también hay una inmunidad psicológica, psíquica. La enfermedad psíquica se refiere a la capacidad que las personas tenemos de responder a distintas crisis, adversidades de la vida, ahí cada uno se comporta de una manera diferente y eso demuestra la capacidad personal que tienes de defenderte ante esta crisis. Lo que vemos es que, en el plano biológico, el virus avanzó mucho y muy rápido por esta escasez de inmunidad previa. Desde el punto de vista psíquico, nos encontramos 
con una población, en América Latina en general y en las grandes concentraciones urbanas de Europa, Estados Unidos, con sujetos que tienen una baja inmunidad psíquica porque vienen de una historia, en el caso nuestro, Argentina, y me imagino que también en el de Chile y mucho más brutalmente en Brasil, de una cantidad de dificultades económicas, de pobreza y desamparo social que han ido haciendo que muchas personas tengan menos capacidad de atravesar esta situación de crisis. Si pensamos que la emergencia del trastorno despierta síntomas a nivel psíquico, como ansiedad, depresión, pánico, angustia, estos están muy ligados a los recursos que las personas tienen para enfrentar la adversidad.

Hay un debilitamiento de las defensas de la población en dos niveles. En un nivel tenemos a la gente más pobre y vulnerable por razones más bien económicas y de pobreza, son poblaciones más vulnerables; pero por otro lado tenemos a la población de sectores medios, que en este contexto también es vulnerable porque cayó en las políticas del mercado y del neoliberalismo, que han construido un sujeto que ha centrado su vida en sí mismo, lo que llamamos un individualismo más extremo. Entonces tiene una dependencia mucho mayor de las políticas del mercado y lo que pasa ahora es que tiene mucho menos poder para gestionar su vida.

La seguridad psíquica de las personas depende básicamente de dos condiciones: una es el ingreso económico y es importante, porque eso a muchas personas le da certezas y le hace sentir que tienen dominio de su vida. El otro más importante todavía es el acompañamiento emocional, afectivo; cuando una persona tiene una red emocional, familia, amigos, grupo de compañeros/as, actividades donde comparte la vida, tiene un mayor nivel de seguridad y de recursos para enfrentar esta situación. Esto está mostrando ser muy relevante en la Argentina, por lo menos en la lucha contra la epidemia. Vemos una población más vulnerable que resiste muy bien porque se ha puesto en una situación muy solidaria; es notable cómo las propias personas que viven en asentamientos, villas miseria, han tenido rápidamente una respuesta solidaria y han entrado a lo que llamamos una "cuarentena comunitaria" en sus propios barrios: se aseguran ellos en su relación con el exterior al barrio y tenemos un bajo índice, todavía, de circulación del virus en estos conjuntos poblacionales. Da la impresión de que esta respuesta aporta mucho a la inmunología de estas personas, no solo la inmunología psíquica, porque también mejora la respuesta física y corporal a la infección. Pero es un sector que sin duda va a ser afectado y da la impresión de que está teniendo mucha mejor respuesta defensiva a este virus. El sector más vulnerable, donde el virus está dañando más, es el de la clase media, algunos media-alta, que son individuos que hace años han construido esto que llamamos "sujeto liberal". ¿Qué les pasa a estas personas? Han apostado a entregar gran parte de la gestión de sus vidas al mercado, repudian al Estado y 
todo lo que provenga del Estado. Entonces compran seguros de salud, el famoso tema de prepago, por lo que dejan en manos privadas su salud, pagando cifras muy importantes. En segundo lugar, acuden a las escuelas privadas, desechan la escuela pública porque desprecian lo que viene del Estado y tienen a sus hijos en escuelas privadas. En tercer lugar, lo que es la protección social, que tiene que ver con el sistema de jubilaciones, hacen lo mismo: sacan seguros privados, que son ideas de los bancos y las empresas de seguros. Estas personas se encuentran en una situación muy dramática porque tienen toda su seguridad dependiendo de estas instituciones y, a la vez, las instituciones las van a hacer depender del ingreso económico en cuanto no logran pagar seguros de salud que son caros, suelen ser de un 20, 25 por ciento del ingreso de estas personas, que se ven enfrentadas a tener que recurrir al Estado y a los hospitales públicos, lo cual significa un choque muy grande y una humillación muy grande. Lo mismo ocurre con la educación, están sacando a los chicos de escuelas privadas para llevarlos a las escuelas públicas, lo cual es vivido como una situación de pérdida muy grande. Se ven muy angustiados frente al futuro porque no cuentan con un sistema solidario que el Estado garantiza, dependen de algunos de los seguros que han contratado en la medida en que puedan pagar y seguir pagando. Esto generó una vulnerabilidad muy grande y muy especial en las clases medias en estos momentos, por lo menos en la Argentina y en España, donde trabajo también: se está produciendo una incertidumbre, angustia, crisis de pánico, depresión, hay una ruptura enorme. En este escenario creció rápidamente la dificultad para la convivencia, se está generando violencia y están apareciendo más femicidios que antes. Nos da la impresión, a quienes trabajamos en salud mental, de que vamos a recibir mucha más demanda de estos sectores que, probablemente, de los sectores socialmente más vulnerables.

\section{-Para nosotros, en Chile, resulta más que pertinente lo que señala. ¿Dónde queda este sujeto liberal en el nuevo contexto de exigencias que impone una pandemia y que requiere un Estado fuerte? Un tema que se ha planteado son las consecuenias del distanciamiento fisico, que fue nombrado primero como distanciamiento social. ¿Ustedes han podido pensar en eso?}

Primero, en la etimología no existe el término de distanciamiento social, es un término que han acuñado ahora, pero no existe. Significa atenuar, de algún modo, la exposición al contagio, y el acatamiento en Argentina de la cuarentena ha sido de más del 94 por ciento, las personas entraron rápidamente como medio de protección, pero esto trae conflictos, problemas en la convivencia, a veces, por los espacios reducidos. Por ejemplo, esto es una medida muy inteligente en Argentina: en los 
barrios humildes, asentamientos y villas miseria, las personas cumplen la cuarentena no en su casa, sino que en su barrio, circulan en su barrio, hacen las compras, este aislamiento lo gestionan colectivamente. Además, estos sectores vulnerables están contando con un respaldo del Estado muy grande, cosa que no tienen los sectores medios. Esta gente se siente muy respaldada porque el Estado ha cubierto la necesidad alimentaria, la falta de ingresos, distribuyendo dinero en los bolsillos de la gente fuertemente, con lo cual vemos que hay una aceptación y una defensa de la cuarentena: realmente confían en que el Estado les está protegiendo en esta etapa.

Obviamente, es falso decir que la cuarentena es la causa, la incertidumbre que ha puesto en riesgo la epidemia es la vulnerabilidad de la vida y el riesgo, y lo que ocurre es que esto destruye mucho los proyectos de vida, sobre todo en los sectores medios. En los sectores más humildes están acostumbrados a enfrentarlos, a atravesar crisis de pobreza, de desempleo, han atravesado muchos momentos críticos en su vida, están más preparados/as porque tienen el ejercicio de esto, es una crisis más. Pero para los sectores medios esto es nuevo, porque tenían proyectos muy centrados en la economía y en la acumulación de un ahorro que les iba a permitir viajes, sostener todos estos pagos, entonces les rompe el proyecto de futuro, por eso estamos viendo mayores crisis en los sectores medios, porque la vida se les rompió más violentamente. Los proyectos de vida centrados en la economía van a ser lo más dañado una vez que pase la epidemia.

Entonces, yo diría “cuidado", están partiendo con una premisa falsa, no es cierto que el daño sea por el distanciamiento físico. De entrada, cuando se planteó esta idea de que había que atender o la economía o la salud, se trató de una dicotomía falsa: hay que proteger la salud para tener una economía que siga funcionando. Lo que ocurre es que hay gente que siente más el daño en su economía porque su vida está puesta en la economía y desprecian el tema de la salud.

Ahí tienen las consecuencias que están atravesando en Brasil, que quiso seguir esa idea de que había que defender la economía para no dañarla. La economía se va a dañar igual porque la crisis a nivel de la salud y de la vida la va a dañar de todas maneras, como dijo acá el presidente nuestro, que la economía se recupera, pero de la muerte nadie sale. Entonces, lo que hay que cuidar es que la gente no se muera, no que pierda dinero, pero ahí se ven las ideologías de mercado, que siempre tienen un horizonte en que vale más la defensa de la economía y el dinero que la vida de las personas. Lo hacen con la vida de los otros/as y a veces con la vida propia, pero generalmente con la vida de los otros/as. En este momento, lo que más daña son los despidos en las fábricas. Aquí hay un sistema en que está prohibido el despido y es obligatorio mantener el sueldo de las personas que están en cuarentena, y las empresas pequeñas que no pueden sostener los sueldos están cubiertas por el 
Estado, esa es una política de seguridad social. Si la cuarentena se interrumpe, no con criterios epidemiológicos, sino que económicos, se está poniendo en crisis todo el sistema, los criterios propios de la epidemiología son los sistemas de cuidado y protección, lo otro es un tema político, no epidemiológico.

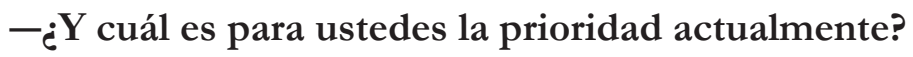

Bueno, nosotros estamos trabajando la idea que está en todo el mundo: poner al Estado en primer plano. El Estado, que es el único que tiene la capacidad de generar una protección social y de salud adecuada, pues el mercado no puede atender ni la salud ni puede atender la idea de vulnerabilidad social o la necesidad de protección social. Entonces, cómo el Estado va a tener que elaborar políticas públicas. Lo que estamos trabajando mucho es que desde acá se puede salir utilizando lo que la gente está viviendo en la epidemia, generando más políticas sociales de solidaridad. Por ejemplo, lo que existe en los centros sociales, hay que fomentar lo que hacen los clubes de barrio, que son lugares importantes para la salud mental y la elaboración más colectiva de la crisis, hay que aumentar de nuevo los centros vecinales o agrupaciones de jubilados. Es decir, potenciar lo que está siendo, ha sido y va a ser la solidaridad necesaria para atravesar todas las dificultades. Si el Estado apoya esos proyectos, evidentemente vamos a tener muchas más herramientas para que la gente recupere capacidades conductivas y logre atravesar esta situación.

Es más complejo con los sectores medios, que van a tener más crisis, pero en eso las políticas públicas tienen que tratar de buscar una manera y facilitar que estas personas vuelvan a tener un respaldo del Estado, educación pública gratuita y para todos/as, salud pública gratuita, tiene que haber una jubilación solidaria que esté garantizada por el Estado, esas son las políticas que van a tener que seguir muchos Estados. Hasta un diario de derecha de Londres está diciendo esto mismo, que hay que avanzar hacia políticas de Estado que generen solidaridad institucional para todos. Hay que ver cómo se las arreglan los gobiernos liberales que quieren trabajar en el sentido opuesto.

La gente está descubriendo que el Estado es el que puede generar el piso de soporte para vencer esta crisis, también la gente de los sectores medios. A mucha de esta gente que tiene salarios medios altos no les va a alcanzar para cubrir el pago privado de la salud, educación, etc. Van a tener que recurrir al Estado. Lamentablemente, les va a dar vergüenza ir al Estado, porque siempre habían sido dueños de la gestión personal de sus vidas, se van a dar cuenta de que van a necesitar de lo que representa el Estado, que es el único que puede garantizar una solución solidaria a los problemas de la vida. Nunca el mercado puede garantizar eso. 


\section{$-¿$ ¿Cómo están trabajando en estos momentos?}

En Argentina, en general, hay una red de atención primaria de salud que tiene distintos grados de desarrollo en cada provincia, pero en general es el primer nivel de atención, la mayor cantidad de las consultas entra ahí, también ahora, con el problema de los contagios, el primer lugar son estos centros de atención primaria. Luego está la red de hospitales públicos y Argentina tomó una medida por ley, en que incorporó todo el sistema de atención de privados, eso significa incorporar a las clínicas, sanatorios, sanatorios de obra social de los gremios, a la salud pública, o sea, tienen que atender también el tema de la infección. Esto, en Argentina, está teniendo buenos resultados, porque nosotros tenemos en este momento una disponibilidad de terapia intensiva, o sea, de cuidados intensivos, hay una disponibilidad de mil camas en el país y se están equipando otras 2.500 camas. ¿Por qué Alemania tuvo un índice de muertes de 1,8 por ciento, similar al de China y España, pero en Inglaterra fue de 12 por ciento y en Estados Unidos de 18 por ciento? La razón son los sistemas de salud, no tenían los recursos adecuados para atender la gravedad. Los responsables de gran parte de las muertes en estos países son los sistemas de salud que tenían, no la enfermedad.

En Francia, España, Estados Unidos, Inglaterra han tenido que asumir el fracaso en el sistema de salud, han salido a buscar la ayuda de China, que es la que está proveyendo gran parte de los recursos para ampliar los servicios. Lo han dicho en el diario ultraliberal de Inglaterra, lo dicen los periódicos de Estados Unidos, el Estado falló como responsable de la salud de la población.

Estados Unidos empezó no haciéndose cargo de que tenían problemas de una enfermedad infecciosa grave, como si fuera China la que tenía el problema del virus y no Estados Unidos, y luego dijeron que el responsable era la OMS (Organización Mundial de la Salud) por el manejo que tuvo de la epidemia. Es una manera de concentrar y desplazar el problema a otro lado y no hacerse cargo de los fallos que tuvo, de entrada, en el manejo de la epidemia, y esto le está costando muy caro y está pasando las 40 mil muertes, eso es muy grave. Este es el costo de no haber empezado asumiendo la responsabilidad frente a la epidemia, se lo están diciendo los gobernadores de distintos estados. Cuando el gobierno de Barack Obama enfrentó el A(H1N1) (2008-2009) hubo un acuerdo de Obama con el gobierno chino de instalar un laboratorio común de estudio de estos virus en China y se hizo un acuerdo, un estudio conjunto de esas epidemias nuevas que están ocurriendo. Una de las primeras cosas que hizo Trump fue traer a todo el equipo norteamericano desde China, desactivó el programa, con lo cual perdió la posibilidad de tener una información rápida cuando comenzaron los primeros episodios de la crisis. No les 
importa. Uno está escuchando cosas terribles, como esta idea extraña de que es mejor que la gente se infecte para desarrollar inmunidad a costa de la muerte de los viejos, claro, la que se muere es la población mayor. Están postulando que los mayores no estén ocupando camas que pueden ocupar los jóvenes, es un criterio económico, si no producen, no hay que gastar plata en ellos. Ojo, que eso se está escuchando en Brasil y Estados Unidos, donde lo dicen públicamente: no invertir dinero del Estado en cuerpos inútiles que no aportan para nada en la economía nacional, eso es muy grave, impresentable.

\section{-A propósito de esta pandemia se hace evidente que hay gobiernos que efectivamente piensan que hay vidas desechables.}

Claro, eso es desde el siglo XIX hasta hoy, está claro que para el capitalismo los cuerpos útiles son aquellos que son productivos, que producen economía. Los otros son cuerpos inútiles y una carga social, los discapacitados, pobres, personas ignorantes, con menores capacidades cognitivas. En el siglo XIX, ya explícitamente el capitalismo los llamaba "los cuerpos inútiles", de hecho, a partir de esa idea diseñaron los primeros grandes encierros: los manicomios tenían que ver con los cuerpos inútiles, lugares para oligofrénicos, personas con discapacidad cognitiva o los infecciosos en la época de las epidemias, los tuberculosos. El capitalismo hizo siempre eso, no es nuevo, pero claro, escandaliza escucharlo de nuevo. Es lo que ocurre cuando se desechan cuerpos inútiles de las empresas, donde aquellas personas que no se pueden adaptar a las nuevas tecnologías quedan desechadas. Gran parte de lo que se llama "especificación laboral” es sacar del sistema productivo a personas que tienen incapacidad de acoplarse a estas exigencias de las nuevas tecnologías, no es nuevo, es del capitalismo, no creo que eso cambie mucho por la epidemia.

En salud mental trabajamos persona con persona, nuestro problema es siempre una persona y nuestra política es que una persona adquiera un soporte social que le permita llevar adelante su vida y que no se enferme, esto significa que algunas de las personas que tengan capacidad de sumarse a un conjunto social se integren a la vida social y que de algún modo sean escuchadas en la singularidad de la vida. Me parece que la epidemia nos pone frente a ese desafío, era nuestra línea de trabajo siempre en salud mental, pero ahora vamos a tener que profundizarla, vamos a tener que pensar más en estrategias de tipo comunitario, solidario, y en cómo ayudamos a que la gente pueda generar lo que llamamos una especie de autoorganización en las propias comunidades para que puedan defenderse en aquellos lugares donde pueden demandar al Estado cobertura social. Pero bueno, hay que esperar cómo 
sigue después esta historia, ¿no? Ustedes, en Chile, tienen un movimiento de demandas sociales muy fuerte que quedó un poco interrumpido. Pero justamente después de esta crisis viene una demanda social muy fuerte, un reclamo al Estado en cuanto a las políticas de tipo social, salud, educación, jubilación, son los tres pilares que el neoliberalismo quiso destruir. Cuando hablan de reducir el Estado es que no quieren que se gaste, que cada uno se haga cargo de su salud, educación y jubilación, y eso va a generar una demanda social muy fuerte, muy fuerte, la demanda hacia el Estado va a ser mucho mayor. 


\section{REFERENCIAS}

Agüero, Maria José (2017). Salud mental y ciudadanía: la composición de un nosotros. Edtorial Universitat Autónoma de Barcelona Departament de Psicologia Social.

Cepal (2020). Informe sobre el impacto económico en América Latina y el Caribe de la enfermedad por coronavirus (COVID-19). En: https://repositorio. cepal.org/bitstream/handle/11362/45602/1/S2000313_es.pdf

Pujal i Llombart, Margot (2018). Cap. 8. Apuntes para una "salud mental” inclusiva: duelo a la identidad de género y reconocimiento de la heterogeneidad de la experiencia. En M. Teresa Climent Clemente y Marta Carmona Osorio (coords.) (2018), Transpsiquiatría. Abordajes queer en salud mental. Asociación Española de Neuropsiquiatría, Madrid.

Reguillo, Rossana (2017). Paisajes insurrectos: jóvenes, redes y revueltas en el otoño civilizatorio. Ned ediciones, 2017, México.

Universidad de Chile (2020). Salud mental en situación de pandemia. Documento para Mesa Covid-19. En: https://www.uchile.cl/portal/especiales/ covid19/163020/estrategia-nacional-para-salud-mental-propuesta-a-mesasocial-covid-19

Versi, Andrea (2018). Entrevista con Emiliano Galende. En: http://www. revistadiagnosis.org.ar/index.php/diagnosis/article/view/45 